\title{
The creation of a computational model of corrugated beams using the author's program "GOPRO"
}

\author{
Vadim Alpatov $^{1 *}$, Alexey Lukin ${ }^{1}$, and Irina Laguta ${ }^{1}$ \\ ${ }^{1}$ Samara State Technical University, Academy of Architecture and Civil Engineering, \\ Molodogvardeyskaya St., 194, Samara, 443001, Russia
}

\begin{abstract}
The program «Gofro» is intended for the automated generation of data on the geometrical scheme of the beam with corrugated or plane web for further use in design complexes. The program has got a window interface, and it consists of one module for the input of feed da-ta, for calculation and for the display of its results in txt file format. The program offers a possibility to choose the outline of the structure, the profile of the web, the type of cross-section, and to set other parameters of the structure. When building up the model with the help of the author program «Gofro» and GMSH preprocessor for the automatic genera-tion of finite element mesh, the correctness of geometrical shape of elements is monitored by the algorithms that are input in the preprocessor. The author compares the time re-quired to create the models using the author program and GMSH preprocessor and using the standard resources of «Lira» software system. The authors performed numerical studies of various I-beams created in the program «GOPRO».
\end{abstract}

\section{Introduction}

In the practice of designing load-bearing structures it is quite often necessary to consider several design solutions, which differ in a number of parameters. Speaking about the design of a beam with corrugated web, such parameters are the profile, length and height of the corrugation. It should be noted that the creation of the design scheme of the beam with corrugated web is rather a time-consuming task, especially in those cases when the height of the beam's section changes along the length of the element, or when there are holes in the web [1-20]. Some recommendations on the mathematical modeling for beams with corrugated web can be found in the works $[21,22]$.

In order to reduce the labor cost for building up the design model, the author program «Gofro» [23] was developed, that allows automatically generating the design model for the beam, and inputting these data into different complexes («ANSYS», «CalculiX», PC «Lira», PC «SCAD», etc.) with the help of a text document with the required data encoding.

\footnotetext{
Corresponding author: avu75@mail.ru
} 


\section{Materials and methods}

The program «Gofro» is intended for the automated generation of data on the geometrical scheme of the beam with corrugated or plane web for further use in design complexes. The program has got a window interface, and it consists of one module for the input of feed data, for calculation and for the display of its results in txt file format. The program offers a possibility to choose the outline of the structure, the profile of the web, the type of crosssection, and to set other parameters of the structure. When building up the model with the help of the author program «Gofro» and GMSH preprocessor for the automatic generation of finite element mesh, the correctness of geometrical shape of elements is monitored by the algorithms that are input in the preprocessor. The author compares the time required to create the models using the author program and GMSH preprocessor and using the standard resources of «Lira» software system.

The program is written in $\mathrm{C}++$, software development environment is Borland $\mathrm{C}++$ Builder 6. To date, the program has only one Russian language interface (Figure 1).

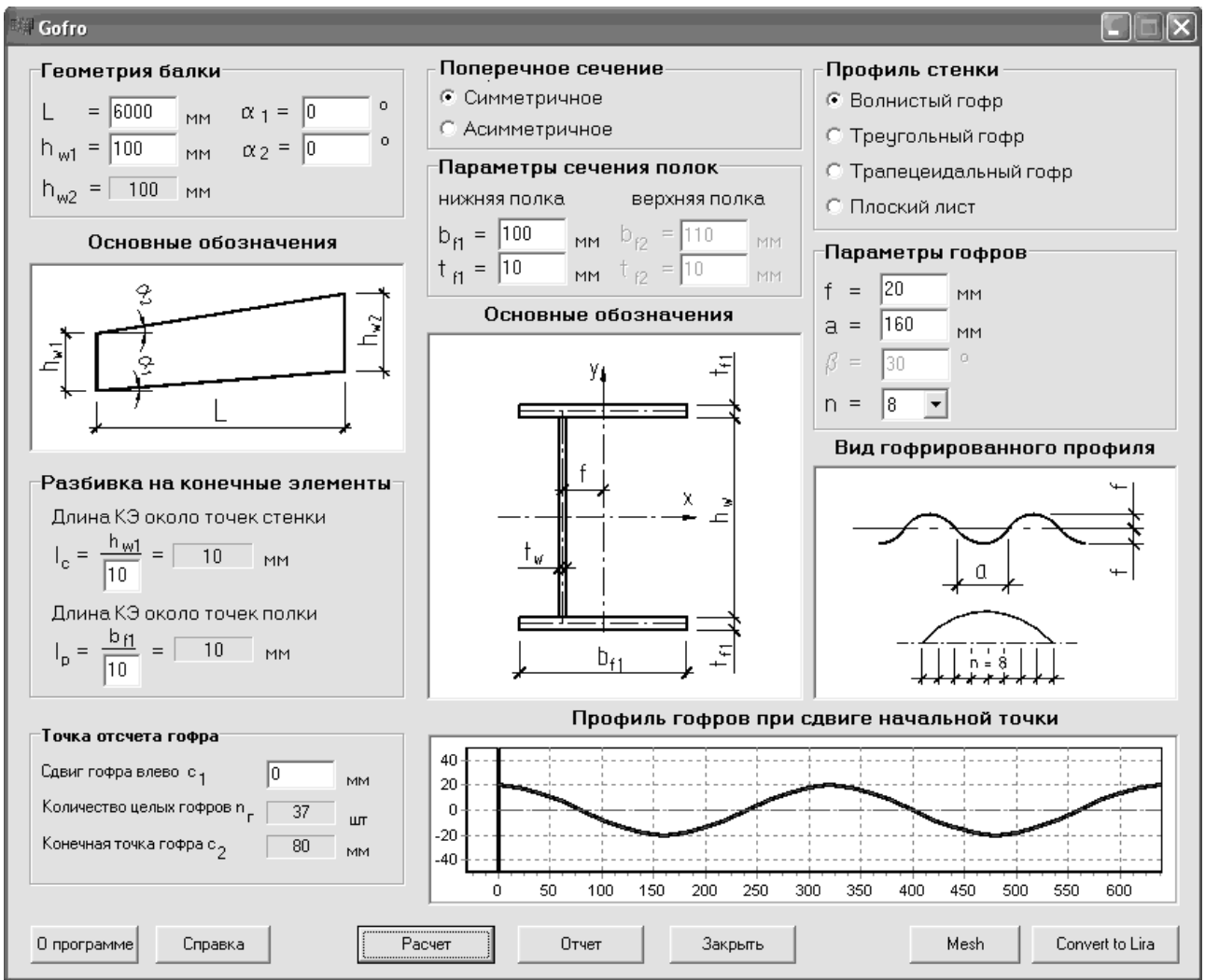

Fig. 1. Program for the preparation of the geometry of the model for the beam with corrugated web.

Out of the wide range of corrugation shapes, the ones that are widely used in international practice are the vertical corrugations with three kinds of outline [24, 25]. And they were selected for use in the program (Figure 2). In this case, if you set the height of the wave $f=0$, you can obtain a beam with plane web.

Determination of the points position, as well as joining the points together with lines, is designed as a loop. For each outline of the corrugation an algorithm of its own is input in the position determination procedure. Wavy corrugation is described by the trigonometric function $\cos (x)$. 

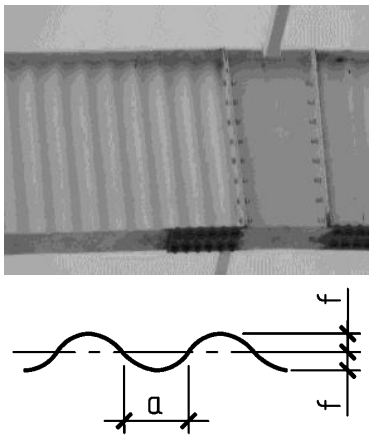

Wavy
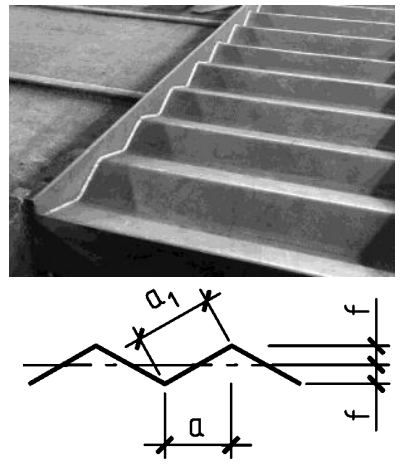

Triangular
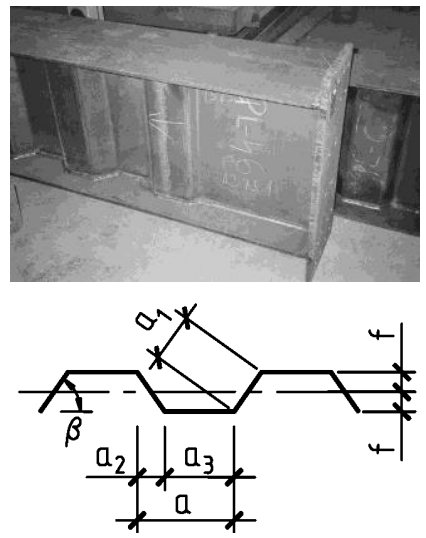

Trapezoid

Fig. 2. Outline of corrugated web.

The program offers the possibility to set the change of sectional height along the length of the beam, as well as to choose the symmetrical or asymmetrical cross-section.

Inputting the beam's scheme into a certain design system has got its own peculiar features. This is connected with the possibilities of the calculation program. For example, «Ansys» has got its own generator of finite element (FE) mesh, while PC «Lira» uses an intermediate program (eg, GMSH [26]) to get the FE mesh, followed by data conversion.

To show the ways to reduce the time spent on building up the model, let's consider the following example.

Example. Let's create the model for the beam with vertically corrugated web and make the calculations using PC «Lira» in two ways:

1 - with the help of the author program «Gofro» and GMSH;

2 - using PC «Lira» internal resources.

Basic geometrical properties: span $L=3 \mathrm{~m}$; web height $h_{\mathrm{w}}=200 \mathrm{~mm}$; flange width $b_{\mathrm{f}}=200 \mathrm{~mm}$; the outline of the corrugation is wavy: semi-wave length $a=150 \mathrm{~mm}$; semiwave height $f=40 \mathrm{~mm}$; FE lateral length $-20-25 \mathrm{~mm}$ (Figure 3).
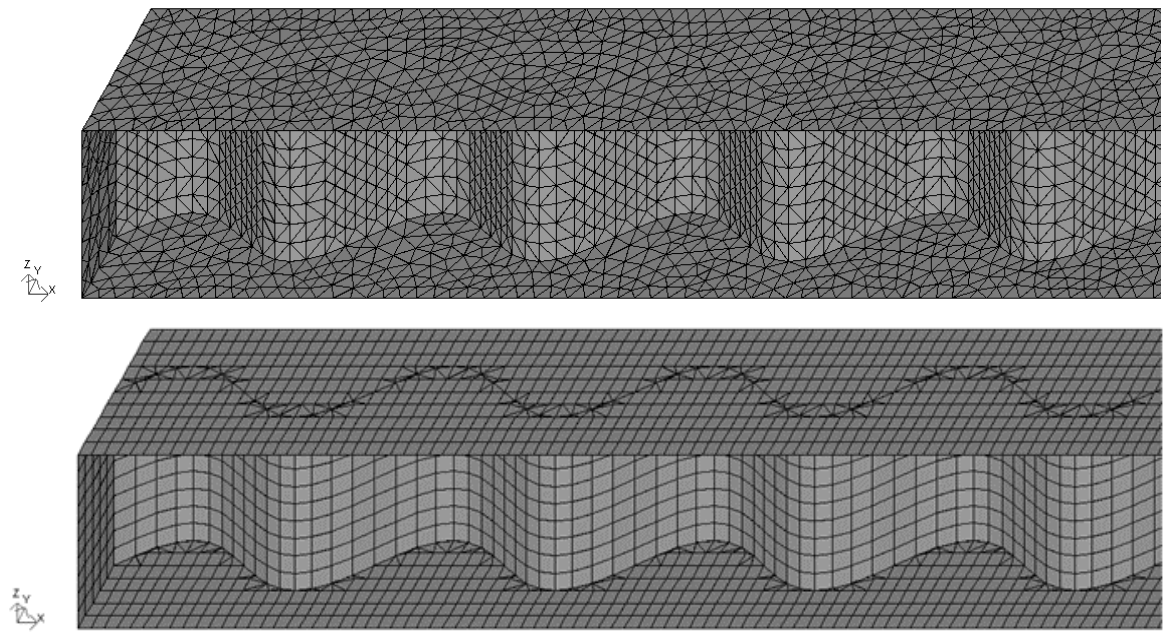

Fig. 3. The models for the beam with corrugated web made using PC «Lira»:

a - with the help of the author program «Gofro» + GMSH;

$\mathrm{b}-$ using PC «Lira» internal resources. 
Table 1. Comparison of the time spent on building up the design model.

\begin{tabular}{|c|c|c|}
\hline $\mathbf{N}$ & Program & $\begin{array}{c}\text { Time spent, } \\
\text { min }\end{array}$ \\
\hline 1 & $\begin{array}{c}\text { «Gofro»+GM } \\
\text { SH } \rightarrow \text { PC } \\
\text { «Lira» }\end{array}$ & $5-8$ \\
\hline 2 & PC «Lira» & $22-30$ \\
\hline
\end{tabular}

The compared results (Table 1) show that the time spent on building up the design model can be reduced 4-6 times. This depends mainly on the outline of the corrugation and on the value of FE.

It should also be noted that building up the model using the resources of PC «Lira» requires setting the correct parameters of $\mathrm{FE}$, which is especially true for triangular elments, and only in this case the calculation results will be reliable. When building up the model using the author program «Gofro» and GMSH preprocessor, this is not required, since during the automatic generation of FE mesh, the correctness of the elements' geometrical shape is monitored.

It should be noted that using the program «GOFRO», solution of the problem does not lose accuracy in the software package «Lira».

\section{Conclusions}

1. The developed program «Gofro» facilitates the preparation of data on the geomtry of the design model for beams with vertical corrugated web.

2. The time spent on building up the model for the beam with vertical corrugated web can be reduced up to 6 times using the author program «Gofro».

3. Because using the program "GOFRO", solution of the problem does not lose accuracy in the software package «Lira».

\section{References}

1. I.S. Kholopov, et al, Tradition and Innovation in Civil Engineering and Architecture: Proceedings of the 72nd all-Russian Scientific and Technical Conference, pp. 15-17 (2015)

2. I.S. Kholopov, et al, Tradition and Innovation in Civil Engineering and Architecture: Proceedings of the 72nd all-Russian Scientific and Technical Conference, pp. 68-71 (2015)

3. I.S. Kholopov, et al, Tradition and Innovation in Civil Engineering and Architecture: Proceedings of the 72nd all-Russian Scientific and Technical Conference, pp. 18-19 (2014)

4. L.I. Kuznetsov, A.A. Aktuganov, A.P. Trofimov, News of KSUAE 1, pp. 117-121 (2010)

5. A.S. Poltoradnev, Bulletin of Civil Engineers of SPSUACE. Architecture. Construction. Transport 4, pp. 175-179 (2012)

6. I.I. Krylov, A.N. Kretinin, News of Higher Educational Institutions. Construction 6, pp. 11-14 (2005)

7. T.L. Dmitrieva, H. Ulambaiar, News of Higher Educational Institutions. Investment. Construction. Real Estate 4, pp. 132-139 (2015)

8. V.Yu. Alpatov, Patent for utility model RUS 111172 (2011) 
9. V. Alpatov, et al, Patent for utility model RUS 31252 (2003)

10. A. Lukin, V. Alpatov, et al, Bulletin of SSAU. Urban planning and architecture 2, pp. 4-9 (2016)

11. A.A. Levchuk, Modern metal and timber building structures. Scientific Proceedings 1, pp. 179-184 (2008)

12. S.M. Petrov, Building Mechanics and Structures Calculation 4, pp. 27-33 (2010)

13. S.M. Petrov, Building Mechanics and Structures Calculation 1, pp. $23-28$ (2013)

14. A.R. Rzhanitsin, Compound bars and plates (Moscow: Stroyizdat) (1986)

15. I.S. Kholopov, M.D. Mosesov, et al, Higher education establishments news. Building Engineering 2, pp. 108-112 (2008)

16. S.M. Petrov, E.V. Ildiyarov, et al, Industrial and civil engineering 6, pp. 44-47 (2009)

17. S.M. Petrov, KiSP Program. Certificate of software registration RUS 2012614613 (2009)

18. M. Balzannikov, I. Kholopov, et al, Procedia Engineering 11, pp. $72-81$ (2015)

19. I. S. Kholopov, et al, Building materials, equipment, technologies of XXI century 1, 66-68 (2008)

20. I. S. Kholopov, et al, Science and education in the XXI century. Collection of scientific papers based on materials of the International Scientific-Practical Conference 34, 145147 (2013)

21. I.S. Rybkin, Industrial and Civil Construction 4, pp. 53-54 (2008)

22. M.S. Barabash, Modern technologies of calculations and design for metal and wooden structures (Moscow: ASV) (2010)

23. A. Lukin Certificate of software registration RUS 2012618070 (2012)

24. A. Soloviev, et al, Vestnik MGSU 11, pp. 105-112 (2012)

25. A. Lukin, A. Soloviev, Construction Bulletin of Russian Academy of Engineering 11, pp. 196-206 (2010)

26. C. Geuzaine, J. Remacle, International Journal for Numerical Methods in Engineering 11, pp. 1309-1331 (2009) 